\title{
Rapid baso-apical translocation of Mycobacterium avium ssp. paratuberculosis in mammary epithelial cells in the presence of Escherichia coli
}

\author{
D. G. G. Schwarz, ${ }^{*}$ F. M. Shoyama, $†$ L. L. Oliveira, $\ddagger$ S. Sreevatsan, $\nmid$ and M. A. S. Moreira*1 \\ *Department of Veterinary, Universidade Federal de Viçosa (UFV), CEP 36570-900, Viçosa, Minas Gerais, Brazil \\ †Department of Pathobiology and Diagnostic Investigation, Michigan State University, East Lansing 48824 \\ ‡Department of General Biology, Universidade Federal de Viçosa (UFV), CEP 36570-900, Viçosa, Minas Gerais, Brazil
}

\begin{abstract}
Infection of mammary gland cells with bacterial pathogens begins with adhesion, invasion, and persistence within the cells or systemic distribution. Some bacteria, such as Escherichia coli, are known to causes bovine mastitis, resulting in acute proinflammatory responses in the mammary tissue. Mycobacterium avium ssp. paratuberculosis (MAP), the etiological agent of paratuberculosis, is able to spread to distant organs after crossing intestinal cells, reaching the mammary gland and potentially being released in milk, infecting calves during suckling. Its exit from systemic sites may be influenced by preexisting inflammation such as that caused by $E$. coli mastitis. Interactions between $E$. coli and MAP in mammary epithelial cells have not yet been described. In this study, we posited that E. coli-infected bovine mammary epithelial cells would facilitate basoapical translocation of MAP in an ex vivo model. We showed that the presence of E. coli in a bovine mammary epithelial cell line (MAC-T) increased baso-apical translocation of MAP to the apical side of the cells. Levels were significantly higher 30 min post-infection and decreased at $120 \mathrm{~min}$ post-infection. Cells previously infected with $E$. coli and MAP or with $E$. coli alone showed a significant increase in IL1B mRNA expression at $120 \mathrm{~min}$. We detected no significant expression of p38 mitogen-activated protein kinase (mapkp38) or IL10, regardless of treatment. Thereby, the presence of E. coli in MAC-T cells alters the translocation of MAP through epithelial cells, enabling its rapid translocation to the cellular surface. Expression of $I L 1 B$ was shown to influence the apical-basal translocation of MAP at 120 min. Findings from the current study suggest that MAP translocation into milk is likely enhanced by
\end{abstract}

Received October 5, 2017.

Accepted February 20, 2018.

${ }^{1}$ Corresponding author: masm@ufv.br inflammatory states such as those induced during $E$. coli mastitis. This is the first report demonstrating the effect of $E$. coli under MAP coinfection in bovine mammary epithelial cells under experimental conditions.

Key words: mammary gland, mastitis, coinfection, paratuberculosis

\section{INTRODUCTION}

Mycobacterium avium ssp. paratuberculosis (MAP) is the etiological agent of paratuberculosis (Johne's disease), which mainly affects ruminants. The disease is characterized by an incurable chronic granulomatous enteritis, resulting in diarrhea, progressive intestinal emaciation, dehydration, and death (Collins, 2003; Lombard, 2011). Infected animals may excrete MAP in the feces or milk. Thus, milk intake from infected cows facilitates the transmission of MAP to calves, which are the most susceptible to infection (Patel and Shah, 2011). It has been proposed that MAP does not multiply efficiently within intestinal epithelial cells. The presence of MAP in these cells is considered a transitional phase until the macrophages are recruited to the infection site where MAP can subsequently infect them (Lamont et al., 2012). Thus, mammary epithelial cells may be a potential reservoir of MAP for susceptible animals during milking intake. Although it has been inferred that MAP might not cause inflammation in the mammary gland (Larsen and Miller, 1978), the microorganism has been found inside the cytoplasmic vacuoles of bovine mammary epithelial cells, as it is observed in infected bovine macrophages (Patel et al., 2006). However, its interactions with other microorganisms have been poorly studied. Recently, dead yeast and yeast cell wall components from Saccharomyces cerevisiae have been found to decrease the effectiveness of MAP binding in bovine mammary epithelial cells under experimental conditions ( $\mathrm{Li}$ et al., 2016). This suggests that these components could contribute to the reduction of the risk of MAP infection in the mammary gland. 
Another disease that affects a large part of the world's dairy herds and inflicts great economic losses in the dairy industry (Bradley, 2002) is mastitis, an inflammation of the mammary gland. Mastitis caused by Escherichia coli usually results from environmental contamination and is characterized by an intense immune response with acute and limiting clinical manifestations (Bradley and Green, 2001). Escherichia coli strains from persistent bovine mastitis can invade mammary epithelial cells more efficiently than strains from transient mastitis, resulting in recurrent mastitis due to the presence of $E$. coli inside these cells or in biofilms (Dogan et al., 2006; Costa et al., 2012; Silva et al., 2014). Mastitis can induce a systemic response, including alterations to the transcriptional profile of distant organs, such as the liver, which may respond by releasing acute phase proteins into the bloodstream (Jiang et al., 2008) as well as a local response, with uninfected mammary gland quarters reacting to the infected quarters (Jensen et al., 2013). In addition, coinfection may alter the infective capacity in epithelial cells. Yang et al. (2016) demonstrated that coinfection of Candida albicans and enterohemorrhagic E. coli in Caco-2 cells increased the invasiveness and upregulation of virulent genes as $P L B 1$ and SAP4, confirming a potential role of these genes in enterocyte cell damage.

The cellular response to infection takes into account the type of pathogenic microorganism and the type of cell challenged. In mammary epithelial cells, MAP can use phagosome acidification and IL1 $\beta$ production as a strategy to chemoattract macrophages to enable translocation from the mucosal side to the basal surfaces to establish infection (Lamont et al., 2012). Within macrophages, MAP has the ability to prevent phagosomal acidification by inhibition of activation of the vacuolar $\mathrm{H}^{+}$-ATPase (Arsenault et al., 2014). In addition, after membrane binding by toll-like receptor (TLR)-2, MAP activates signaling pathways capable of producing cytokines that modulate the immune response. Mitogenactivated protein kinases (MAPK) are stress-activated kinases that are activated by TLR-2 signaling. Among them, MAPK-p38 has been shown to play an important role in the suppression of the antimicrobial response in macrophages (Weiss et al., 2008). It also induces the production of an anti-inflammatory cytokine, IL-10. Together, MAPK-p38 and IL-10 act to suppress the antimicrobial response and immune response, leading to the persistence of MAP within macrophages (Souza et al., 2006; Bannantine et al., 2015). Exposure of cells, including epithelial cells, to LPS stimuli results in TLR-4 recognition and activation of the nuclear factor (NF)- $\kappa \mathrm{B}$ pathway in a MyD88-dependent mechanism, leading to transcription of genes related to innate and inflammatory responses (Asehnoune et al., 2004).
A study by Wilson et al. (1993) found that new cases of subclinical mastitis and chronic infection were lower in MAP-positive cows and demonstrated that the rate of infection Staphylococcus aureus and Serratia spp. was reduced in cows with paratuberculosis. Although these results suggested a possible interaction between MAP and bacteria isolated from bovine mastitis, studies of this relationship have not been reported. The objectives of this work were (1) to determine whether infection with or exposure to $E$. coli of mammary epithelial cells would enable baso-apical translocation of MAP, and (2) to evaluate the cytokines responsible for the signaling pathway in host cells.

\section{MATERIALS AND METHODS}

\section{Bacterial Strains and Culture Conditions}

Mycobacterium avium ssp. paratuberculosis strain K-10 and Escherichia coli isolated from milk from a case of bovine mastitis at the Laboratory of Udder Health (Minnesota Veterinary Diagnostic Laboratory, University of Minnesota, Saint Paul) were used in this experiment. The MAP strain was maintained in Middlebrook 7H9 (MB7H9) broth containing $0.2 \%$ glycerol, $10 \%$ oleic acid dextrose-catalase, and mycobactin J (2 $\mathrm{mg} / \mathrm{L}$ ) (Allied Monitor Inc., Fayette, MO) at $37^{\circ} \mathrm{C}$ for 6 wk at $200 \mathrm{rpm}$ until reaching an optical density (OD) at $600 \mathrm{~nm}$ of 0.5 (equivalent to $1.0 \times 10^{6} \mathrm{cfu} / \mathrm{mL}$ ). The MAP culture was determined to be free of contaminating organisms by the absence of growth of colonies on plaques in brain-heart infusion (BHI) medium. The culture was tested for purity by plating on BHI agar to confirm no growth on overnight inoculation and using the standard IS 900 PCR for MAP. A single colony of E. coli grown on plaque with Luria-Bertani medium was subcultured in Luria-Bertani broth at $37^{\circ} \mathrm{C}$ and centrifuged at 5,000 $\times \mathrm{g}$ after reaching an $\mathrm{OD}_{600}$ of 0.3 $\left(1.0 \times 10^{8} \mathrm{cfu} / \mathrm{mL}\right)$ and used in all cell infection assays.

\section{Bovine Mammary Epithelial Cells}

The bovine mammary epithelial cell line MAC-T, widely used in infection experiments (Bouchard et. al., 2013; Assis et al., 2015), was cultured in a T75 culture flask (TPP Techno Plastic, St. Louis, MO) in Dulbecco's modified Eagle medium (DMEM; GibcoBRL, Grand Island, NY) supplemented with $10 \%$ fetal bovine serum (FBS) and $1 \%$ penicillin $(5,000 \mathrm{U} / \mathrm{mL})$ streptomycin $(5,000 \mu \mathrm{L} / \mathrm{mL})($ Gibco/Life Technologies, Carlsbad, CA). The MAC-T cells were incubated in humidified chamber at $37^{\circ} \mathrm{C}$ in $5 \% \mathrm{CO}_{2}$ until monolayer confluency. Confluency was assessed by visualization under phase-contrast microscopy. 


\section{Translocation Assay}

The supernatant of confluent MAC-T cells was discarded, $3 \mathrm{~mL}$ of TrypLE Express (Gibco/Life Technologies) was added, and the flask was incubated at $37^{\circ} \mathrm{C}$ for 10 min to resuspend adhered cells. Approximately $3.0 \times 10^{5} \mathrm{MAC}-\mathrm{T}$ cells were added to the apical side of Transwell inserts $(6.5 \mathrm{~mm}$ in diameter, 3.0- $\mu \mathrm{m}$ pore size Transwell permeable support; Corning, Lowell, MA) and incubated in DMEM containing $10 \%$ FBS and $1 \%$ penicillin-streptomycin (Gibco/Life Technologies). Cell monolayer integrity was verified by the following methods: (1) visualization by phase microscopy, (2) measurement of transepithelial resistance (>132 $\Omega$ ) by trans-epithelial electric resistance (EVON, World Precision Instruments Inc., Sarasota, FL), (3) monolayer crystal violet staining, and (4) trypan blue $(0.25 \%)$ permeability assay (OD at $540 \mathrm{~nm})$, as previously described (Sangari et al., 2000; Bermudez et al., 2002; Patel et al., 2006).

Before the coinfection experiment, the confluent cells were washed 3 times with preheated $\left(37^{\circ} \mathrm{C}\right)$ PBS (pH 7.2; D-PBS Dulbecco's PBS 1×, Gibco/Life Technologies). For the infection, $1 \mathrm{~mL}$ of $E$. coli cultured in Luria-Bertani broth $\left(1.0 \times 10^{8} \mathrm{cfu}\right)$ was centrifuged at $13,000 \times g$ for $5 \mathrm{~min}$. The pellet was washed twice with PBS, resuspended in $200 \mu \mathrm{L}$ of DMEM (with $10 \%$ FBS, without antimicrobials), added to the upper chamber, and incubated at $37^{\circ} \mathrm{C}$ in a humidified chamber with $5 \% \mathrm{CO}_{2}$ for $30 \mathrm{~min}$. For this assay, the integrity of the monolayer was previously standardized after $30 \mathrm{~min}$ of exposure to $E$. coli by the methods described above. Then, the compartment was washed twice with PBS and $200 \mu \mathrm{L}$ of DMEM (with 10\% FBS, without antimicrobials) was added. For the lower chamber, $1 \mathrm{~mL}$ of MAP K-10 culture $\left(\mathrm{OD}_{600}=0.5\right.$, equivalent to $1 \times 10^{6}$ $\mathrm{cfu} / \mathrm{mL}$ ) was centrifuged at $13,000 \times g$ for $5 \mathrm{~min}$ and washed twice with PBS. Subsequently, the pellet was resuspended in $750 \mu \mathrm{L}$ of DMEM (10\% FBS, without antimicrobials), and vortexed for $5 \mathrm{~min}$. The MAP suspension was then passed through a sterile 21-gauge needle 20 times to break the bacterial clumps and, after $5 \mathrm{~min}$ of sedimentation, the upper three-fourths of solution was used for infection. The supernatant with suspended MAP was placed in the lower chamber and incubated at $37^{\circ} \mathrm{C}$ in a humidified chamber for 10,30 , and $120 \mathrm{~min}$. Then, the supernatant from the upper chamber was collected for culture and other molecular biology procedures. Positive controls were cells infected only with $E$. coli and cells infected only with MAP. Uninfected cells served as negative controls. To evaluate the cell stimulatory capacity and its influence on MAP translocation, the experiment was carried out by adding E. coli LPS $(0.5 \mu \mathrm{g} / \mathrm{mL}$; Sigma-Aldrich, St.
Louis, MO). Unchallenged cells were used as control. All assays were carried out in triplicate each on 3 independent occasions.

\section{MAP Culture}

Initially, antibiotics and their appropriate concentrations were standardized to be added in the MAP culture medium capable of inhibiting the growth of $E$. coli, but not MAP. Two antimicrobials widely used in the treatment of bovine mastitis, nalidixic acid and ampicillin, in different concentrations $(10,50$, and 100 $\mu \mathrm{g} / \mathrm{mL}$ ) were included in MB7H9 agar containing $0.2 \%$ glycerol, $10 \%$ oleic acid dextrose-catalase, and mycobactin J $(2 \mathrm{mg} / \mathrm{L})$. We found that ampicillin at $50 \mu \mathrm{g} /$ $\mathrm{mL}$ was inhibitory for E. coli but tolerated by MAP. Thus, previously collected supernatants from the upper chamber were centrifuged at $12,000 \times g$ for 5 min, resuspended in $100 \mu \mathrm{L}$ of $0.9 \%$ saline solution, serially diluted, and plated onto MB7H9 agar with ampicillin $(50 \mu \mathrm{g} / \mathrm{mL})$ for colony counts.

\section{DNA Extraction}

To obtain DNA from the supernatant of the upper chamber, samples were first centrifuged at 12,000 $\times g$ for $5 \mathrm{~min}$ and washed twice with PBS (pH 7.2). For DNA extraction, the DNeasy blood and tissue kit (Qiagen, Valencia, CA) was used following the manufacturer's recommendations, with modifications. Briefly, after centrifugation, samples were treated with $200 \mathrm{~mL}$ of $2 \%$ lysozyme and $20 \mathrm{~mL}$ of proteinase $\mathrm{K}$ (Promega, Madison, WI); for MAP cell wall rupture, the samples were treated with $0.1-\mathrm{mm}$ zirconia/silica beads at 7,000 rpm 3 times for $50 \mathrm{~s}$ each in the MagNaLyser (Roche Life Science, Indianapolis, IN). Then, the samples were centrifuged at $13,000 \times g$ for $5 \mathrm{~min}$ and $200 \mu \mathrm{L}$ of ice-cold ethanol was added. The remaining procedures were in accordance with the protocol of the DNeasy kit manufacturer as follows. Transfer sample to QiaAmp column (Qiagen, Valencia, CA), centrifuge at 13,000 $\times$ $g$ for $3 \mathrm{~min}$. Discard flow-through and replace column back inside collection tube. Follow the protocol in accordance with the kit manufacturer. Add 30 to $50 \mu \mathrm{L}$ of nuclease-free water to column and incubate at room temperature for $2 \mathrm{~min}$.

\section{RNA Extraction}

Infected MAC-T cells and controls adhered on the Transwell membrane were washed with PBS, homogenized with $500 \mu \mathrm{L}$ of TRIzol reagent (Invitrogen, Carlsbad, CA) for cell disruption and maintenance of RNA integrity, and stored at $-80^{\circ} \mathrm{C}$ for later use. All 
Table 1. Sequences of forward $(F)$ and reverse $(R)$ primers used in real-time PCR

\begin{tabular}{|c|c|c|}
\hline $\begin{array}{l}\text { Gene and } \\
\text { direction }\end{array}$ & Sequence $\left(5-3^{\prime}\right)$ & Reference \\
\hline mapkp38, F & TGCTTGTCCTGTTCTCTTCG & Lamont and Sreevatsan, 2010 \\
\hline mapkp38, R & GGAAGGTCTTCACTGGCAAA & Lamont and Sreevatsan, 2010 \\
\hline$I L 1 B, \mathrm{~F}$ & ATCTTCGAAACGTCCTCCGAC & Buza et al., 2003 \\
\hline IL1B, R & ССТСТССТTGCACAAAGCTCA & Buza et al., 2003 \\
\hline IL10, F & GTGATGCCACAGGCTGAGAA & Buza et al., 2004 \\
\hline IL $10, \mathrm{R}$ & CGCCTTGCTCTTGTTTTCG & Buza et al., 2004 \\
\hline$A C T B,{ }^{1} \mathrm{~F}$ & CGCCATGGATGATGATATTGC & Okumu et al., 2010 \\
\hline$A C T B, \mathrm{R}$ & AAGCCGGCCTTGCACAT & Okumu et al., 2010 \\
\hline
\end{tabular}

${ }^{1}$ Housekeeping gene.

materials and surfaces were previously treated with RNase Away (Molecular Bioproducts, San Diego, CA). For RNA extraction, the Direct-zol RNA MiniPrep kit (ZymoResearch, Irvine, CA) was used, following the manufacturer's recommendations. The RNA was treated directly in the extraction column spin with DNase I reaction mix (ZymoResearch) as described by the manufacturer. The RNA quality and concentration were determined by measuring the ratio $260 \mathrm{~nm} / 280 \mathrm{~nm}$ on a NanoDrop ND 1000 spectrophotometer (Nanodrop Products, Wilmington, DE).

\section{cDNA Synthesis}

The cDNA was synthesized using the SuperScript III First-Strand Synthesis SuperMix for qRT-PCR kit (Invitrogen) according to the manufacturer's recommendations. A final concentration of $400 \mathrm{ng}$ of cDNA in $20 \mu \mathrm{L}$ was obtained.

\section{Quantitative Real-Time PCR}

Absolute quantification was performed using LightCycler 480 SYBR Green I Master in a LightCycler 480II (Roche, Madison, WI) with its respective software. The primer set secA F (5'-GCGCAAGGTGATCTACGC-3') and secA R (5'-GCGCAAGGTGATCTACGC- $\left.3^{\prime}\right)$ was previously constructed for amplification of a 63bp fragment (Janagama et al., 2010). The total PCR reaction was $20 \mu \mathrm{L}$, with $10 \mu \mathrm{L}$ of Mastermix $(2 \times$; component of LightCycler 480 SYBR Green I Master), $1 \mu \mathrm{L}$ of each primer $(10 \mu M), 3 \mu \mathrm{L}$ of nuclease-free water, and $5 \mu \mathrm{L}$ of DNA (template). For quantification, a standard curve was constructed with MAP genomic DNA sequentially diluted 10 -fold and determining the number of copies per dilution $\left(10^{8}, 10^{7}, 10^{6}, 10^{5}, 10^{4}\right.$, $10^{3}, 10^{2}$, and $10^{1}$ copies). The mass of a MAP DNA copy was calculated using the following equation: $m$ $=(n) \times\left(1,096 \times 10^{-21} \mathrm{~g} / \mathrm{bp}\right)$, where $n$ is the size of the genome and $m$ is the mass of the genome. For each reaction, a standard curve was constructed to relate the cycle threshold $(\mathbf{C t})$ values to the number of copies.

Relative quantification was performed using LightCycler 480 SYBR Green I Master on the LightCycler 480II (Roche) with its respective software. For the reaction, $10 \mu \mathrm{L}$ of Mastermix $(2 \times), 1 \mu \mathrm{L}$ of each primer $(10$ $\mu M$; Table 1), $1 \mu \mathrm{L}$ of cDNA (20 ng), and nuclease-free water were used in a final volume of $20 \mu \mathrm{L}$. The following program was used: denaturation at $95^{\circ} \mathrm{C}$ for $5 \mathrm{~min}$ and PCR at $95^{\circ} \mathrm{C}$ for $10 \mathrm{~s}, 60^{\circ} \mathrm{C}$ for $10 \mathrm{~s}$, and $72^{\circ} \mathrm{C}$ for $10 \mathrm{~s}$ for 40 cycles. All target expressions were normalized by the constitutively expressed $\beta$-actin gene $(A C T B)$. The results of the mean values of the $\mathrm{Ct}$ obtained by triplicates were used to calculate the relative gene expression of the target genes by the comparative method, using the formula $2^{-\Delta \Delta \mathrm{Ct}}$ (Livak and Schmittgen, 2001).

\section{Statistical Analysis}

Each experiment was carried out in triplicate and repeated 3 times. The results are shown as means \pm standard deviations. The results were analyzed by ANOVA, and the interactions between variables were verified by the Tukey test, using Graphpad Prism software (Graph Pad Inc., La Jolla, CA) with statistical significance at $5 \%$.

\section{RESULTS}

\section{Passage Time of MAP Through MAC-T Cells}

The MAP DNA from the upper chamber was quantified by absolute quantitative real-time (qRT)-PCR, and all standard curves were linear up to 8 orders of magnitude, with correlation coefficients around 0.99. In Figure 1, the number of copies of MAP in relation to different times is shown. The passage of MAP through MAC-T cells was more efficient $(P<0.05)$ when cells were previously infected with $E$. coli. A significant increase in MAP translocation was observed at 10 and 
30 min compared with 120 min post-infection in the presence of $E$. coli. Regardless of the time of infection, we observed no effect of LPS on MAP transepithelial migration. We cultured the supernatant from the upper chamber onto MB7H9 agar with ampicillin (50 $\mu \mathrm{g} /$ $\mathrm{mL}$ ) for MAP colony counts; however, no colonies were observed, regardless of time of infection.

\section{IL1B Expression in MAC-T Cells During Coinfection}

The mRNA expression of cytokines, including $I L 1 B$, mapkp38, and IL10, was quantified in epithelial cells following MAP exposure for different infection periods. Expression of $I L 1 B$ was significantly higher $(P<0.05)$ when E. coli was present in the MAC-T cells (Figure 2A). Cells infected with $E$. coli only showed an upregulation in expression of $I L 1 B$ at $30 \mathrm{~min}$, which was significant $(P<0.05)$ at $120 \mathrm{~min}$. When the cells were infected with $E$. coli and MAP, this increase was significant at 120 min post-infection. In Figure 2B, IL10 mRNA expression was upregulated from $30 \mathrm{~min}$ and then decreased at $120 \mathrm{~min}$. Although these observations were not statistically significant $(P>0.05)$, it is important to note that, unlike the other treatments, MAP-infected cells had increased expression of IL10 from 30 min post-infection. Similar to results for $I L 10$, expression of MAPK-p38 was not significant (Figure $2 \mathrm{C})$. In addition, stimulatory treatments using LPS with MAP or LPS only did not result in significant changes in expression of the investigated genes.

\section{DISCUSSION}

Coinfection in epithelial cells may occur by interaction between distinct pathogens such as viruses (Márquez et al., 2016), bacteria (Bukholm and Kapperud, 1987), yeast (Yang et al., 2016), and parasites (Reynolds et al., 2017). However, the study of coinfection is complex because of the different factors related to infection route, target cell, type of pathogens, and intensity of the immune and inflammatory response. In bovine mastitis, coinfection may result in exacerbation of inflammatory stimuli, which would not occur at the same intensity for infections with a single bacterial strain. For example, Stipkovits et al. (2013) verified that Mycoplasma arginini did not cause mastitis resulting in significant SCC, but predisposed animals infected with Streptococcus dysgalactiae to severe mastitis. Thus, coinfection can worsen clinical status, increase treatment costs, reduce milk production, and interfere with mastitis control programs worldwide. Infection of bovine mammary gland cells by MAP can occur both by the systemic route from bloodstream to mammary epithelial cells (descending infection) and by upward

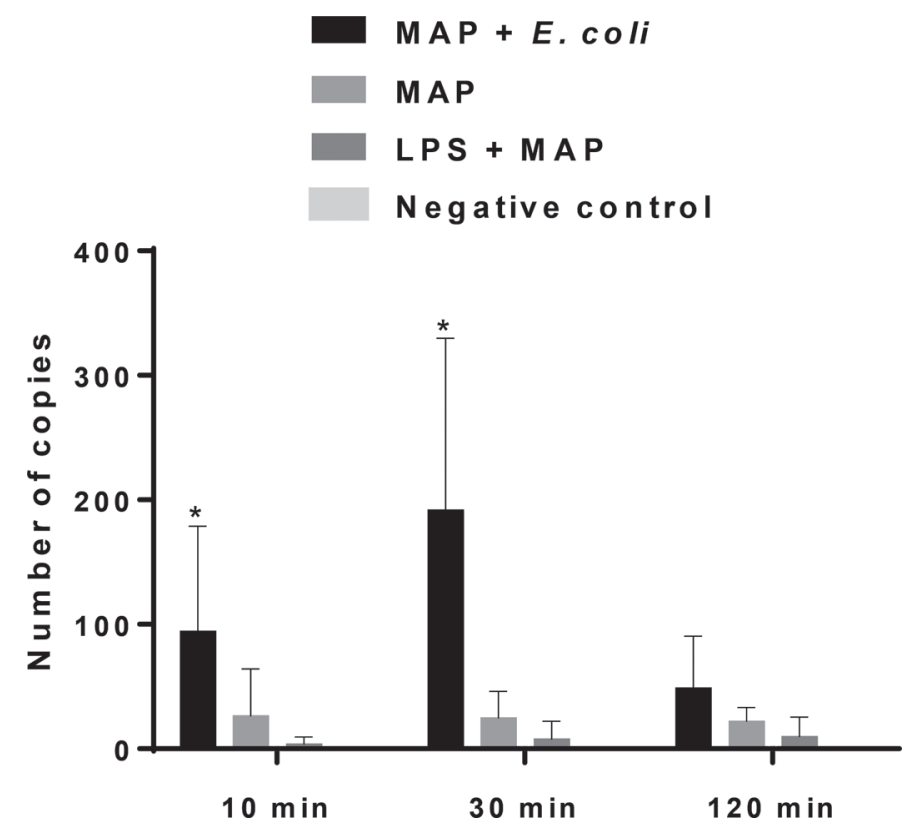

Figure 1. Detection of the number of Mycobacterium avium ssp. paratuberculosis (MAP) from the supernatant of the upper chamber of the Transwell (Corning Inc., Lowell, MA) relative to post-infection times $(10,30$, and $120 \mathrm{~min})$ in different treatments. Bovine mammary epithelial cell line (MAC-T) cells were previously infected with Escherichia coli or LPS-stimulated and subsequently challenged by MAP. Controls used were MAC-T cells challenged only by MAP and unchallenged cells (negative control). Previous E. coli infection in MAC-T cells induced rapid apical-basal MAP translocation at 10 and 30 min postinfection $(P<0.05)$. Apical-basal MAP translocation was verified at 120 min postinfection; LPS had no influence on MAP translocation. The results are shown as means $\pm \mathrm{SD}$. The asterisks indicate a significant difference between treatments $\left({ }^{*} P<0.05\right)$.

contamination of the teat canal (ascending pathway; Patel et al., 2006). Regardless of route of mammary infection, we hypothesized that previous E. coli infection in bovine mammary epithelial cells could facilitate translocation of MAP from subepithelial (basal or systemic) sites to the mucosal region and be released into the milk by the cell with greater efficiency. This idea is supported because it has been shown that $E$. coli has the ability to break down the tight junction barrier in epithelial cells or to alter the permeability of epithelial cells and interfere in the transcription process of virulence genes to a subsequent pathogen (Shifflett et al., 2005; Yang et al., 2016). Furthermore, Bukholm and Kapperud (1987) found synergistic interactions between Campylobacter jejuni and enteroinvasive E. coli in A549 epithelial cells, increasing the internalization of C. jejuni when E. coli was present. Associated with this, the invasive capacity of MAP can be increased by the osmolarity of the medium or previous passage through mammary epithelial cells (Patel et al., 2006). We addressed our hypothesis using a translocation assay, and the amount of MAP in the supernatant from the upper 


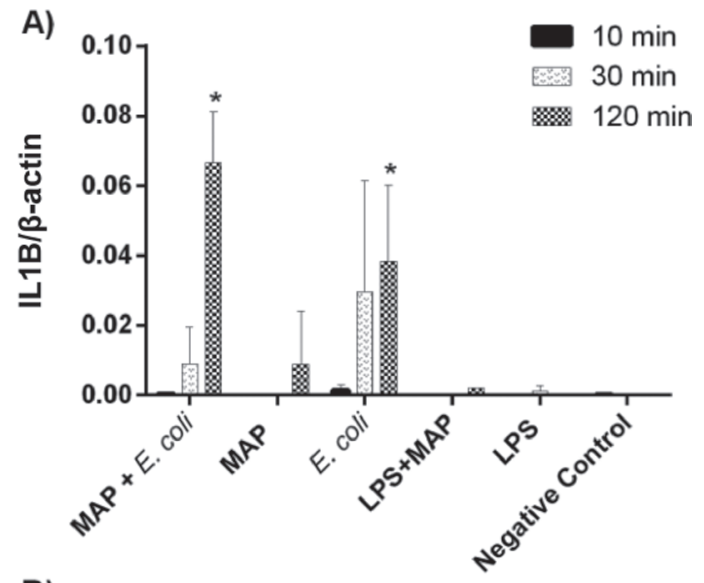

B)

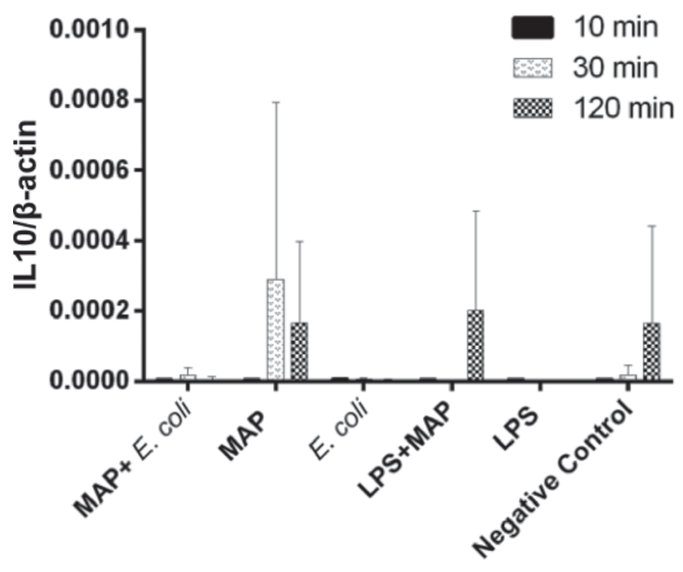

C)

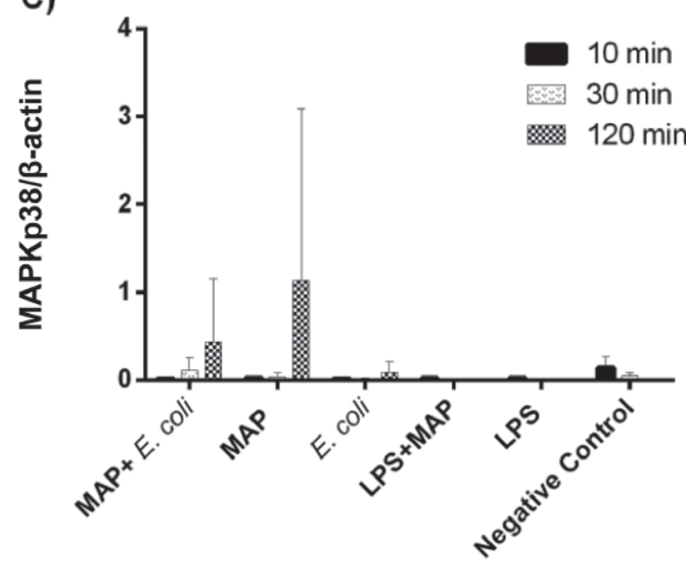

Figure 2. Expression of cytokine mRNA in bovine mammary epithelial cells (MAC-T). Cells were previously infected with Escherichia coli or LPS-stimulated and subsequently infected by Mycobacterium avium ssp. paratuberculosis (MAP) for 10, 30, and $120 \mathrm{~min}$. Controls were cells infected only with $E$. coli or MAP and uninfected (negative control). Treatments with LPS only in MAC-T cells were also performed. All target expressions are shown relative to the constitutive $\beta$-actin gene $(A C T B)$. (A) IL1B mRNA expression was significantly increased $(P<0.05)$ at 120 min post-infection when MAC-T cells were infected with $E$. coli $(\mathrm{MAP}+E$. coli and E. coli); LPS did not stimulate mRNA expression in this experiment; (B) IL10 mRNA expression: not significant; (C) MAPK-p38 mRNA expression: not significant. Error bars represent \pm SD. ${ }^{*}$ The asterisks indicate significant difference across treatments, $P<0.05$. chamber was assayed by qRT-PCR from 10 to $120 \mathrm{~min}$. This period was considered for evaluation because the phagosome acidification process in macrophages occurs after 10 min of MAP infection and is completed by 120 min post-infection (Kugadas et al., 2016).

We verified that prior $E$. coli infection in bovine mammary epithelial cells began the baso-apical passage of MAP up to $10 \mathrm{~min}$ of contact with the cells and increased significantly at $30 \mathrm{~min}$ (Figure 1). This indicates that preexisting $E$. coli infection could alter the mechanism of natural infection in epithelial cells of the mammary gland, enabling facile translocation of MAP from the basal to the apical region. These results corroborated previous studies showing that MAP infection within the mammary gland can be influenced by the extracellular environment (milk) and the presence of coinfections. Li et al. (2016) reported that the presence of Saccharomyces cerevisiae cell wall components interfered in MAP binding to MAC-T cells and to bovine intestinal epithelial cells, reducing their adhesion capacity. Patel et al. (2006) found that when MAP was incubated in raw milk at $37^{\circ} \mathrm{C}$ for $24 \mathrm{~h}$, it had an increased capacity for internalization in MAC-T cells. Lamont et al. (2012) reported that mammary epithelial cells form low-resistance or diffuse tight junctions that can decrease transmembrane resistance. Although monolayer integrity tests, as previously described, were standardized to ensure that $E$. coli exposure for $30 \mathrm{~min}$ did not macroscopically compromise the integrity of the monolayer in our study, it is plausible that previous infection of $E$. coli could reduce the transepithelial resistance of MAP.

The decrease in MAP detection at 120 min in cells previously infected with E. coli (Figure 1) suggests that between 30 and 120 min post-infection, MAP was likely reinternalized, and that the period from 10 to 30 min was significant for rapid MAP internalization and migration to the apical side. In part, these results corroborate those found by Lamont et al. (2012), where rapid MAP internalization and acidification of the phagosome in MAC-T cells occurred between 10 and 30 min. Patel et al. (2006) reported that prior passage of MAP through mammary epithelial cells increased post-invasion in intestinal epithelial cells. Similarly, in the present study, re-invasion of MAP may have occurred because of previous passage of MAP through MAC-T cells.

Lipopolysaccharide is an outer membrane component of gram-negative bacteria that has the ability to stimulate macrophages, monocytes, and the secretion of cytokines such as IL-1, IL-6, and tumor necrosis factor- $\alpha$ (Meng and Lowell, 1997). In addition, Guo et al. (2013) demonstrated that LPS can increase the permeability of intestinal tight junctions without inducing cell death 
in vitro. In the present study, LPS was used at $0.5 \mu \mathrm{g} /$ $\mathrm{mL}$, which might not be enough to stimulate mammary epithelial cells because we observed no influence of LPS on MAP translocation through the cells (Figure 2). Thus, it is not entirely clear how E. coli could be acting in this invasion process because LPS did not act as a positive control for the stimulation of cells. However, the presence of $E$. coli promoted the upregulation of IL$1 \beta$, demonstrating that other components besides LPS are likely important to the invasion process. Future studies are required to elucidate these mechanisms.

Cultivation on solid medium (e.g., Herrold's egg yolk medium or Middlebrook) is the gold standard for MAP detection (Collins et al., 1993). Regardless of the time of infection, we could not identify colonies characteristic of MAP in solid culture medium. Because the amount of MAP DNA detected by qRT-PCR in the supernatant was relatively low, the amount of live MAP in the supernatant was also likely to be low, decreasing the sensitivity of the MAP culture. Similarly, Mitchell et al. (2015) verified that detection by culture had low sensitivity for cows with low levels of fecal shedding.

It is important to evaluate the physical mechanisms involved in the internalization of MAP in nonphagocytic cells (e.g., macropinocytosis) and to identify the cytokines that assist in this process for their contribution to the roles of epithelial cells (the first cell barrier that MAP needs to overcome) in the infective process and inflammatory response. In the present study, evaluation of cytokines revealed that IL-1 $\beta$ was crucial to MAP reinternalization at $120 \mathrm{~min}$ post-infection in the MAC-T cells (Figure 2A). Infection of the mammary gland by $E$. coli triggers an acute inflammatory reaction, with recruitment of neutrophils from the bloodstream to the site of infection to control the infection. This control occurs mainly through the production of proinflammatory cytokines such as tumor necrosis factor- $\alpha$, IL-8, C5a (complement component 5a), and IL-1 $\beta$ (OviedoBoyso et al., 2007). Our results suggest that MAC-T cells previously infected with $E$. coli and subsequently with MAP had increased $I L 1 B$ expression, coinciding with the reduction of MAP in the extracellular region.

One of the main outcomes of stimulation of the MAPK-p38 pathway is increased IL10 gene expression in macrophages. As previously mentioned, IL-10 plays a key role in suppressing the antimicrobial activity of macrophages, mainly due to the inhibition of the $\mathrm{T}$ helper-1 immune response by the downregulation of IL12 (Theus et al., 2005). Although the results for IL-10 were not statistically significant, the presence of MAP alone in MAC-T cells influenced its expression at 30 min. In other words, levels of expression of the antiinflammatory agent IL-10 did not increase when E. coli was present but did increase, albeit not significantly, when MAP was present without E. coli. These results are in accordance by results obtained by Lahouassa et al. (2007), where no upregulation of IL-10 was observed in bovine mammary epithelial cells throughout the time of stimulation by Staphylococcus spp. strains and E. coli. Thus, although IL-10 is detected in milk cells from infected udder with different pathogens, mammary epithelial cells are not the source of this cytokine in milk. However, the regulatory mechanisms of IL-10 depend exclusively on the type of cell challenged, and its level of production is associated with the type and strength of the stimulus (Hussain et al., 2016). Interestingly, based on our nonsignificant results for IL-10, MAP appears to contribute to stimulation of this cytokine in mammary epithelial cells, in contrast to that observed with $E$. coli infection (Lahouassa et al., 2007). In the present study, we verified that $I L 1 B$ was significantly expressed in MAC-T cells, unlike mapkp38 and IL10 (Figure 2B and C). Expression of IL10 is MAPK-p38-dependent; therefore, the nonsignificant expression of MAPK-p38 could explain the nonsignificant expression of IL10.

In the intestine, MAP can be translocated through Peyer's patches or enterocytes. It has been hypothesized that entry through Peyer's patches results in rapid interaction with phagocytic cells and inflammatory response. When MAP interacts with enterocytes, it results in a slow inflammatory response and wide systemic spread (Bermudez et al., 2010). This fact could partly explain our findings, where both MAPK-p38 and IL10 expression were not significant in MAC-T cells infected with both E. coli and MAP in vitro.

Overall, these data suggest that the presence of $E$. coli in MAC-T cells is able to facilitate translocation of MAP from the basal region to the apical region of mammary epithelial cells up to 30 min post-infection. This migration process associated with the presence of intracellular $E$. coli triggers increased transcription of IL-1 $\beta$, which is responsible for attraction of macrophages to the site of infection, but it is also related to the attraction of MAP from the apical region to the basal region. The present study sought to understand the exclusive contribution of bovine mammary epithelial cells in the coinfection process between MAP and E. coli. Further studies should be performed to verify whether co-culture with macrophages would modify this IL-1 $\beta$ stimulation profile and the subsequent attraction of MAP in mammary epithelial cells. Furthermore, we verified that mammary epithelial cells are not only reservoirs but also play an active role in the co-infective process between MAP and $E$. coli. Collectively, these findings support the hypothesis that when cows infected with MAP are co-infected with environmental mastitis by $E$. coli, this infection is able to attract MAP from distant regions such as lamina 
propria or supramammary lymph nodes and increase release of MAP into the glandular alveolus. This is the first study evaluating the relationship of these 2 bacteria in mammary epithelial cells.

\section{ACKNOWLEDGMENTS}

The authors acknowledge the financial support from $\mathrm{CNPq}$ (Conselho Nacional de Desenvolvimento Científico e Tecnológico, Brasília, Brazil), FAPEMIG (Fundação de Amparo à Pesquisa de Minas Gerais, Belo Horizonte, Brazil), and CAPES (Coordenação de Aperfeiçoamento de Pessoal de Nível Superior, Brasília, Brazil). M. A. S. Moreira is supported by CNPq.

\section{REFERENCES}

Arsenault, R. J., P. Maattanen, J. Daigle, A. Potter, P. Griebel, and S Napper. 2014. From mouth to macrophage: Mechanisms of innate immune subversion by Mycobacterium avium ssp. paratuberculosis. Vet. Res. 45:1-15.

Asehnoune, K., D. Strassheim, S. Mitra, J. Y. Kim, and E. Abraham 2004. Involvement of reactive oxygen species in Toll-like receptor 4-dependent activation of NF-kappa B. J. Immunol. 172:25222529 .

Assis, B. S., P. Germon, A. M. Silva, S. Even, J. R. Nicoli, and Y. Le Loir. 2015. Lactococcus lactis v7 inhibits the cell invasion of bovine mammary epithelial cells by Escherichia coli and Staphylococcus aureus. Benef. Microbes 6:879-886.

Bannantine, J. P., J. R. Stabel, E. Laws, M. C. D. Cardieri, and C D. Souza. 2015. Mycobacterium avium subspecies paratuberculosis recombinant proteins modulate antimycobacterial functions of bovine macrophages. PLoS One 10:e0128966.

Bermudez, L. E., M. Petrofsky, S. Sommer, and R. G. Barletta. 2010 Peyer's patch-deficient mice demonstrate that Mycobacterium avium ssp. paratuberculosis translocates across the mucosal barrier via both $\mathrm{M}$ cells and enterocytes but has inefficient dissemination. Infect. Immun. 78:3570-3577.

Bermudez, L. E., F. J. Sangari, P. Kolonoski, M. Petrofsky, and J Goodman. 2002. The efficiency of the translocation of Mycobacterium tuberculosis across a bilayer of epithelial and endothelial cells as a model of the alveolar wall is a consequence of transport within mononuclear phagocytes and invasion of alveolar epithelial cells. Infect. Immun. 70:140-146.

Bouchard, D. S., L. Rault, N. Berkova, Y. Le Loir, and S. Even. 2013 Inhibition of Staphylococcus aureus invasion into bovine mammary epithelial cells by contact with live Lactobacillus casei. Appl. Environ. Microbiol. 79:877-885.

Bradley, A. J. 2002. Bovine mastitis: An evolving disease. Vet. J. 164:116-128.

Bradley, A. J., and M. J. Green. 2001. Adaptation of Escherichia coli to the bovine mammary gland. J. Clin. Microbiol. 39:1845-1849.

Bukholm, G., and G. Kapperud. 1987. Expression of Campylobacter jejuni invasiveness in cell cultures coinfected with other bacteria. Infect. Immun. 55:2816-2821.

Buza, J. J, H. Hikono, Y. Mori, R. Nagata, S. Hirayama, Aodon-Geril, A. M. Bari, Y. Shu, N. M. Tsuji, and E. Momotani. 2004. Neutralization of interleukin-10 significantly enhances gamma interferon expression in peripheral blood by stimulation with Johnin purified protein derivative and by infection with Mycobacterium avium ssp. paratuberculosis in experimentally infected cattle with paratuberculosis. Infect. Immun. 72:2425-2428.

Buza, J. J., Y. Mori, A. M. Bari, H. Hikono, Aodon-Geril, S. Hirayama, Y. Shu, and E. Momotani. 2003. Mycobacterium avium ssp. paratuberculosis infection causes suppression of RANTES, mono- cyte chemoattractant protein 1 , and tumor necrosis factor alpha expression in peripheral blood of experimentally infected cattle. Infect. Immun. 71:7223-7227.

Collins, M. T. 2003. Update on paratuberculosis. 1: Epidemiology of Johne's disease and the biology of Mycobacterium paratuberculosis. Ir. Vet. J. 56:565-574.

Collins, D. M., D. M. Stephens, and G. W. de Lisle. 1993. Comparison of polymerase chain reaction tests and faecal culture for detecting Mycobacterium paratuberculosis in bovine faeces. Vet. Microbiol. 36:289-299.

Costa, J. C. M., I. D. F. Espechit, F. A. Pieri, L. dos A. Benjamin, and M. A. S. Moreira. 2012. Increased production of biofilms by Escherichia coli in the presence of enrofloxacin. Vet. Microbiol. 160:488-490.

Dogan, B., S. Klaessig, M. Rishniw, R. A. Almeida, S. P. Oliver, K Simpson, and Y. H. Schukken. 2006. Adherent and invasive Escherichia coli are associated with persistent bovine mastitis. Vet. Microbiol. 116:270-282.

Guo, S., R. Al-Sadi, H. M. Said, and T. Y. Ma. 2013. Lipopolysaccharide causes an increase in intestinal tight junction permeability in vitro and in vivo by inducing enterocyte membrane expression and localization of TLR-4 and CD14. Am. J. Pathol. 182:375-387.

Hussain, T., S. Z. A. Shah, D. Zhao, S. Sreevatsan, and X. Zhou. 2016. The role of IL-10 in Mycobacterium avium ssp. paratuberculosis infection. Cell Commun. Signal. 14:29.

Janagama, H. K., E. A. Lamont, S. George, J. P. Bannantine, W. W. $\mathrm{Xu}, \mathrm{Z}$. J. Tu, S. J. Wells, J. Schefers, and S. Sreevatsan. 2010 Primary transcriptomes of Mycobacterium avium subsp. paratuberculosis reveal proprietary pathways in tissue and macrophages. BMC Genomics 11:561.

Jensen, K., J. Günther, R. Talbot, W. Petzl, H. Zerbe, H. Schuberth, H. Seyfert, and E. J. Glass. 2013. Escherichia coli and Staphylococcus aureus induced mastitis differentially modulate transcriptional responses in neighbouring uninfected bovine mammary gland quarters. BMC Genomics 14:36.

Jiang, L., P. Sørensen, C. Røntved, L. Vels, and K. L. Ingvartsen. 2008 Gene expression profiling of liver from dairy cows treated intramammary with lipopolysaccharide. BMC Genomics 9:443.

Kugadas, A., E. A. Lamont, J. P. Bannantine, F. M. Shoyama, E. Brenner, H. K. Janagama, and S. Sreevatsan. 2016. A Mycobacterium avium ssp. paratuberculosis predicted serine protease is associated with acid stress and intraphagosomal survival. Front. Cell. Infect. Microbiol. 6:85.

Lahouassa, H., E. Moussay, P. Rainard, and C. Riollet. 2007. Differential cytokine and chemokine responses of bovine mammary epithelial cells to Staphylococcus aureus and Escherichia coli. Cytokine $38: 12-21$.

Lamont, E. A., S. M. O'Grady, W. C. Davis, T. Eckstein, and S. Sreevatsan. 2012. Infection with Mycobacterium avium ssp. paratuberculosis results in rapid interleukin-1beta release and macrophage transepithelial migration. Infect. Immun. 80:3225-3235.

Lamont, E. A., and S. Sreevatsan. 2010. Paradigm redux Mycobacterium avium subspecies paratuberculosis-macrophage interactions show clear variations between bovine and human physiological body temperatures. Microb. Pathog. 48:143-149.

Larsen, A. B., and J. M. Miller. 1978. Mammary gland exposure of cows to Mycobacterium paratuberculosis. Am. J. Vet. Res. 39:19721974.

Li, Z., Q. You, F. Ossa, P. Mead, M. Quinton, and N. A. Karrow. 2016. Assessment of yeast Saccharomyces cerevisiae component binding to Mycobacterium avium subspecies paratuberculosis using bovine epithelial cells. BMC Vet. Res. 12:42.

Livak, K. J., and T. D. Schmittgen. 2001. Analysis of relative gene expression data using real-time quantitative PCR and the 2[-Delta Delta C(t)] method. Methods 25:402-408.

Lombard, J. E. 2011. Epidemiology and economics of paratuberculosis. Vet. Clin. North Am. Food Anim. Pract. 27:525-535.

Márquez, M., C. F. G. Álamo, and J. A. Girón-González. 2016. Gut epithelial barrier dysfunction in human immunodeficiency virushepatitis $\mathrm{C}$ virus coinfected patients: Influence on innate and acquired immunity. World J. Gastroenterol. 22:1433-1448. 
Meng, F., and C. A. Lowell. 1997. Lipopolysaccharide (LPS)-induced macrophage activation and signal transduction in the absence of src-family kinases Hck, Fgr, and Lyn. J. Exp. Med. 185:1661-1670.

Mitchell, R. M., Y. Schukken, A. Koets, M. Weber, D. Bakker, J. Stabel, R. H. Whitlock, and Y. Louzoun. 2015. Differences in intermittent and continuous fecal shedding patterns between natural and experimental Mycobacterium avium subspecies paratuberculosis infections in cattle. Vet. Res. 46:66.

Okumu, L. A., N. Forde, A. G. Fahey, E. Fitzpatrick, J. F. Roche, M. A. Crowe, and P. Lonergan. 2010. The effect of elevated progesterone and pregnancy status on mRNA expression and localisation of progesterone and oestrogen receptors in the bovine uterus. Reproduction 140:143-153.

Oviedo-Boyso, J., J. J. Valdez-Alarcón, M. Cajero-Juárez, A. OchoaZarzosa, J. E. López-Meza, A. Bravo-Patiño, and V. M. Baizabal-Aguirre. 2007. Innate immune response of bovine mammary gland to pathogenic bacteria responsible for mastitis. J. Infect. 54:399-409.

Patel, A., and N. Shah. 2011. Mycobacterium avium subsp paratuberculosis - Incidences in milk and milk products, their isolation, enumeration, characterization, and role in human health. J. Microbiol. Immunol. Infect. 44:473-479.

Patel, D., L. Danelishvili, Y. Yamazaki, M. Alonso, M. L. Paustian, J. P. Bannantine, L. Meunier-Goddik, and L. E. Bermudez. 2006. The ability of Mycobacterium avium ssp. paratuberculosis to enter bovine epithelial cells is influenced by preexposure to a hyperosmolar environment and intracellular passage in bovine mammary epithelial cells. Infect. Immun. 74:2849-2855.

Reynolds, L. A., S. A. Redpath, S. Yurist-Doutsch, N. Gill, E. M. Brown, J. Heijden, T. P. Brosschot, J. Han, N. C. Marshall, S. E. Woodward, Y. Valdez, C. H. Borchers, G. Perona-Wright, and B. B. Finlay. 2017. Enteric helminths promote Salmonella coinfection by altering the intestinal metabolome. J. Infect. Dis. 215:12451254 .

Sangari, F. J., J. Goodman, and L. E. Bermudez. 2000. Mycobacterium avium enters intestinal epithelial cells through the apical mem- brane, but not by the basolateral surface, activates small GTPase Rho and, once within epithelial cells, expresses an invasive phenotype. Cell. Microbiol. 2:561-568.

Shifflett, D. E., D. R. Clayburgh, A. Koutsouris, J. R. Turner, and G. A. Hecht. 2005. Enteropathogenic E. coli disrupts tight junction barrier function and structure in vivo. Lab. Invest. 85:1308-1324.

Silva, V. O., L. O. Soares, A. Silva Júnior, H. C. Mantovani, Y.-F. Chang, and M. A. S. Moreira. 2014. Biofilm formation on biotic and abiotic surfaces in the presence of antimicrobials by Escherichia coli isolates from cases of bovine mastitis. Appl. Environ. Microbiol. 80:6136-6145.

Souza, C. D., O. A. Evanson, and D. J. Weiss. 2006. Mitogen activated protein kinase $\mathrm{p} 38$ pathway is an important component of the antiinflammatory response in Mycobacterium avium ssp. paratuberculosis-infected bovine monocytes. Microb. Pathog. 41:59-66.

Stipkovits, L., M. Somogyi, B. Asvanyi, A. Toth, and S. Szathmary. 2013. Short communication: Role of Mycoplasma arginini in mastitis caused by Streptococcus dysgalactiae. J. Dairy Sci. 96:16611667.

Theus, S. A., M. D. Cave, and K. D. Eisenach. 2005. Intracellular macrophage growth rates and cytokine profiles of Mycobacterium tuberculosis strains with different transmission dynamics. J. Infect. Dis. 191:453-460.

Weiss, D. J., C. D. Souza, O. A. Evanson, M. Sanders, and M. Rutherford. 2008. Bovine monocyte TLR2 receptors differentially regulate the intracellular fate of Mycobacterium avium subsp. paratuberculosis and Mycobacterium avium subsp. avium. J. Leukoc. Biol. 83:48-55.

Wilson, D. J., C. Rossiter, H. R. Han, and P. M. Sears. 1993. Association of Mycobacterium paratuberculosis infection with reduced mastitis, but with decreased milk production and increased cull rate clinically normal dairy cows. Am. J. Vet. Res. 54:1851-1857.

Yang, W., Y. Zhou, C. Wu, and J. Tang. 2016. Enterohemorrhagic Escherichia coli promotes the invasion and tissue damage of enterocytes infected with Candida albicans in vitro. Sci. Rep. 6:37485. 